\title{
Comparison of homogenization and ultrasonication as techniques in extracting attached sedimentary bacteria
}

\author{
W. N. Ellery and M. H. Schleyer \\ Oceanographic Research Institute, P. O. Box 10712 , Marine Parade, 4056 Durban, South Africa
}

\begin{abstract}
Uncertainty of complete recovery of attached bacteria during extraction is a major problem in the enumeration of these microorganisms. Homogenization and ultrasonication are the most commonly used physical techniques of extraction, and each is used on the assumption that it gives maximum yield. Ultrasonication of formalin-fixed sandy sediments using an ultrasonication bath with a frequency range varying between 40 and $50 \mathrm{kHz}$, and with a power output simultaneously varying between 100 and $200 \mathrm{~W}$, was more effective than homogenization at $23000 \mathrm{rpm}$. Ultrasonication destroyed many bacteria and, for the sediment under study, it was estimated that counts obtained after an optimum treatment of $2.5 \mathrm{~min}$ are corrected for inadequacies in the extraction process when multiplied by a factor of 1.44 .
\end{abstract}

\section{INTRODUCTION}

One of the major problems in the enumeration of bacteria attached to sedimentary particles is the uncertainty of complete recovery of the bacteria by different extraction techniques. The sediments are usually manipulated physically, often in conjunction with chemical treatment. Shaking, shaking with glass beads, grinding, homogenization and ultrasonication are some of the physical techniques employed, the last 2 being most frequently used on the assumption that they give maximum yield.

Dale (1974) stated that homogenization consistently yields higher numbers than other techniques, viz. ultrasonication, grinding and shaking by hand with glass beads. Meyer-Reil et al. (1978) showed that shaking by hand, the use of 'Tween' 80 and the use of 'Tween' 80 with flocculents gave $1 \%, 4 \%$ and $5 \%$ respectively of the yield produced by homogenization. Montagna (1982) selected this technique basing his choice on the work of Dale (1974) and Meyer-Reil et al. (1978). Weise and Rheinheimer (1978) conversely selected ultrasonication for the extraction of attached sedimentary bacteria on the basis of earlier investigations (Puleo et al., 1967; Stevenson, 1958; Williams and Slade, 1971; Zvyaginstev and Galkina, 1967). Ultrasonication has also been used by other workers on the assumption that it gives a maximum yield (Dye, 1979; Koop and Griffiths, 1982).

The effectiveness of both homogenization and ultrasonication in extracting attached bacteria was tested in the present study.

\section{MATERIALS AND METHODS}

Sand was collected from surface sediments of a lagoon on the north coast of Natal, South Africa, at a water depth of $60 \mathrm{~cm}$ using perspex corers $15 \mathrm{~cm}$ long and with an inside diameter of $1.2 \mathrm{~cm}$. Each sample was fixed with $1 \mathrm{ml}$ concentrated formalin which was evenly dispersed throughout the column by inserting a spinal needle to the base of the core and slowly injecting formalin into the sand as the needle was withdrawn. Samples were stored at $4{ }^{\circ} \mathrm{C}$ for analysis which was completed within $2 \mathrm{wk}$ of sampling. Sufficient material was collected to establish suitable time intervals for treatment by homogenization and ultrasonication before the comparative tests were performed.

Sterile $(0.2 \mu \mathrm{m}$ filtered) water to which had been added the surfactant 'Tween' 80 at a concentration of $1 \times 10^{-4} \%$ as recommended by Scheraga et al. (1979) was used for procedures such as rinsing, dilution and 
the preparation of the acridine orange dye mentioned below.

In the comparative tests a single sand sample was removed from a corer, placed in a conical flask and rinsed 10 times using $20 \mathrm{ml}$ water each time to remove all the interstitial bacteria. According to Anderson and Meadows (1969), 6 rinses are sufficient for this purpose. The sand was then divided into 2 portions for analysis of the recovery of attached bacteria by homogenization and sonication. To each of these subsamples $200 \mathrm{ml}$ water and $2 \mathrm{ml}$ concentrated formalin was added. Homogenization was performed using a Waring Blender BLE 14 Model 11BL21 at 23000 rpm. Foam produced by the technique after each treatment was allowed to dissipate, after which the sample was resuspended by swirling. Ultrasonication was performed using a Decon FS100 ultrasonication bath which sweeps through a frequency range of 40 to $50 \mathrm{kHz}$ and has a power output which varies simultaneously between 100 and $200 \mathrm{~W}$. Aliquots of $5 \mathrm{ml}$ were removed for observation after each treatment by both homogenization and ultrasonication and were replenished with sterile water to maintain a constant sample volume.

Bacteria were filtered onto $0.2 \mu \mathrm{m}$ Nuclepore filters and counts were performed using the AODC (acridine orange direct count) technique of Hobbie et al. (1977). A sufficient number of organisms was counted to give a count of the mean $+/-10 \%$ at the $95 \%$ confidence level according to Cassell's Graphical Method (Cassell, 1965). The counts were corrected for errors introduced by volume adjustments made to the samples after each treatment.

After homogenization and ultrasonication times of $8 \mathrm{~min}$ and $5 \mathrm{~min}$ respectively, small portions of sand

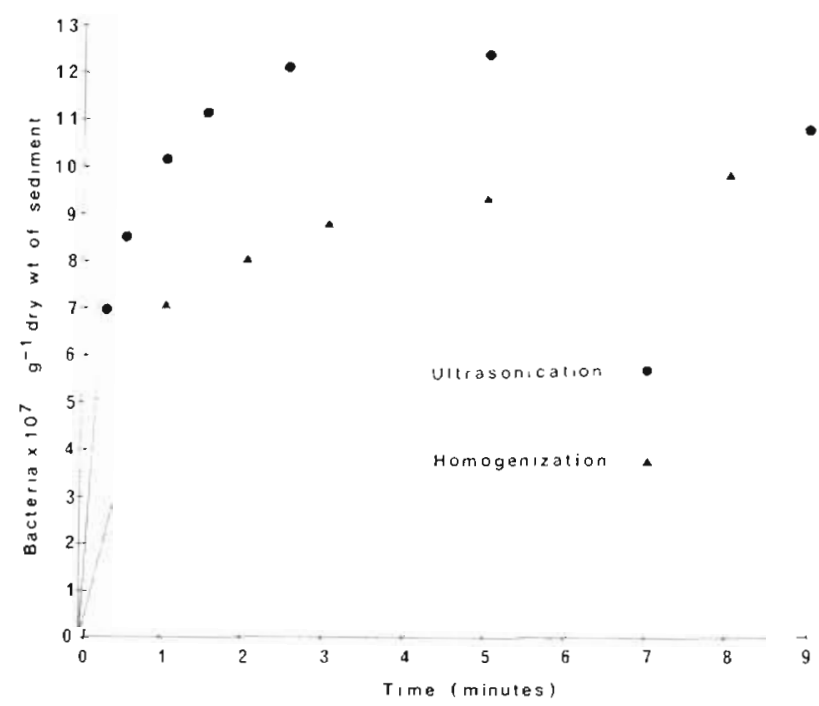

Fig 1. Cumulative yield of attached sedimentary bacteria by homogenization $(\mathbf{\Delta})$ and ultrasonication $(\bullet)$ were removed from each of the subsamples and stained for microscopic observation by the hanging drop method (Frobisher et al., 1974) so that the effectiveness of each technique could be evaluated. The homogenized sample showed significantly greater numbers of bacteria still attached to the sedimentary particles (see 'Results and Discussion'), It was therefore washed again as described above to remove all the interstitial bacteria, $200 \mathrm{ml}$ sterile water was added, and the sample was subjected to ultrasonication to determine the additional effect of this treatment. The sand samples were then oven-dried at $60^{\circ} \mathrm{C}$ for $48 \mathrm{~h}$ so that the number of bacteria per $\mathrm{g}$ dry weight could be calculated.

Finally, the effect of ultrasonication on bacteria was determined. A bacterial suspension obtained by homogenization of a sand core for a period of $2 \mathrm{~min}$, followed by filtration down to a pore size of $2.0 \mu \mathrm{m}$, was treated by ultrasonication for a number of intervals. This was repeated in the presence of ultrasonicated, washed and sterilized sand obtained from the same locality to determine whether the presence of sand had any effect on the results.

\section{RESULTS AND DISCUSSION}

Ultrasonication proved more effective in separating attached bacteria from sand particles than homogenization (Fig. 1). Homogenization of the sand for a period of 8 min gave a yield of ca. $80 \%$ of that produced by ultrasonication for $5 \mathrm{~min}$; this difference was significant at the $5 \%$ confidence level (Student's t-test). Subsequent ultrasonication of the homogenized sample increased the yield by ca. $10 \%$ (Fig. 2), and com-

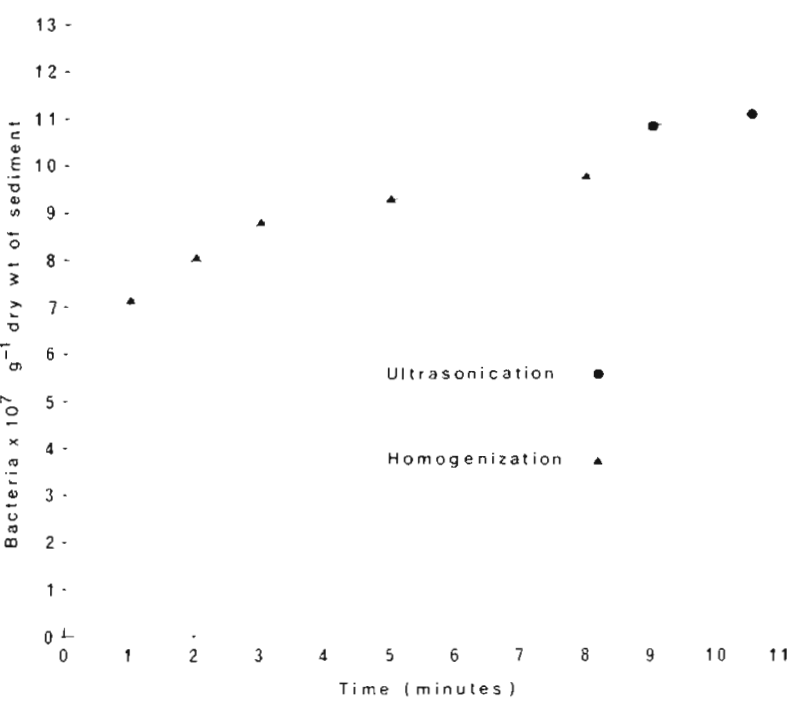

Fig. 2. Curnulative yield of attached sedimentary bacteria by homogenization for $8 \mathrm{~min}(\boldsymbol{\Lambda})$ and subsequent ultrasonication for further $2.5 \mathrm{~min}(\bullet)$ 
parison with the results obtained by ultrasonication for 5 min showed no significant difference at the $5 \%$ confidence level, again using the Student's t-test.

Homogenization has generally been applied for periods of between 5 and $10 \mathrm{~min}$ (Dale, 1974; MeyerReil, 1978; Montagna, 1982) and it was decided to terminate homogenization after $8 \mathrm{~min}$ as a maximum yield was obtained after this period in Montagna's (1982) experiments. In our experiments there was still a considerable yield at this stage. A further $6.5 \mathrm{~min}$ of homogenization would have been required for the yield to reach that obtained by the additional ultrasonication, assuming that the yield would have continued at the rate measured during the last interval of homogenization. Montagna's final time interval which extended from 8 to 16 min resulted in a net reduction in bacterial numbers, and it is possible that an additional $6.5 \mathrm{~min}$ of homogenization would have had a similar effect in our experiments.

Direct observation of sand grains and their attached bacteria after $8 \mathrm{~min}$ of homogenization and $5 \mathrm{~min}$ of ultrasonication, revealed that the former still retained significant numbers of attached bacteria, while on the latter a very limited microbial population remained which became negligible after a further $4 \mathrm{~min}$ of ultrasonication. Residual bacteria could not be quantified due to the variable distribution of the microorganisms. It was also observed that homogenization resulted in the destruction of detrital fragments and damaged many of the sand grains. Large numbers of sand fragments from the homogenized sample were present on the filters on which the bacterial counts were performed.

Ultrasonication proved to be destructive; while there was an increase in the number of suspended bacteria during the first $5 \mathrm{~min}$, organisms were simultaneously being destroyed. This was indicated by the decline in bacterial numbers as treatment continued beyond an equilibrium reached between yield and destruction after $5 \mathrm{~min}$ of ultrasonication (Fig. 1). The loss caused by destruction was measured by ultrasonication of the natural suspension of bacteria (Fig. 3) and it appeared to be due to ultrasonic vibration alone as the presence of sand did not significantly alter the results at the $5 \%$ confidence level when this was tested.

Treatment by ultrasonication should be kept to a minimum because of its destructive nature. Ultrasonication for $2.5 \mathrm{~min}$ yielded $98 \%$ of the bacterial count obtained from 5 min of treatment (Fig. 1) and the shorter treatment proved similarly optimal in a number of preliminary experiments. The graphs of yield and destruction by ultrasonication are combined in Fig. 4, and values of the yield corrected for loss by destruction are included. From Fig. 4 it is possible to estimate a correction factor to convert bacterial counts to the approxi-

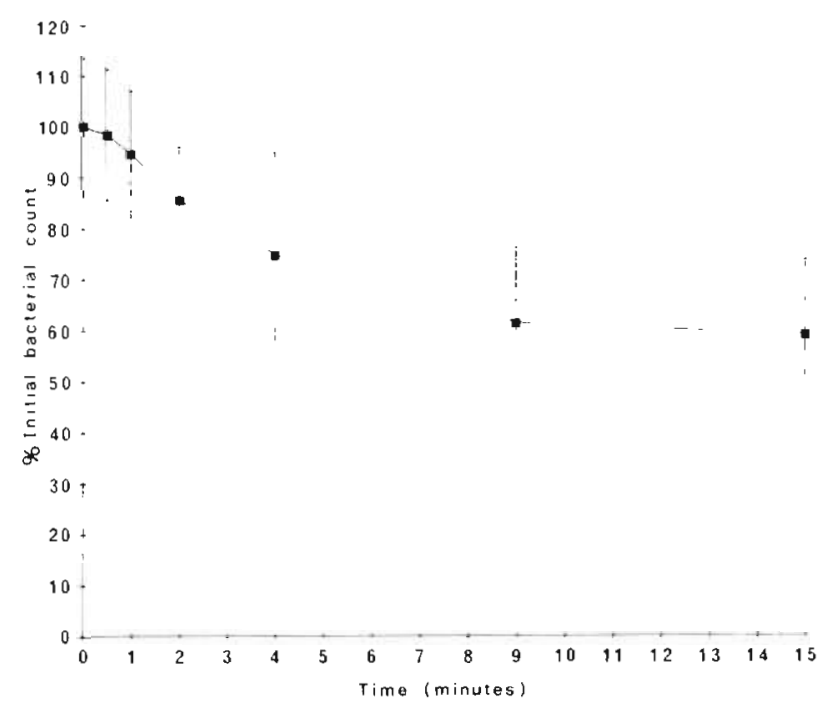

Fig. 3. Destructive effect of ultrasonication on a natural suspension of bacteria extracted from sediments by $2 \mathrm{~min}$ homogenization. Bars: standard deviation around each mean for 4 experiments

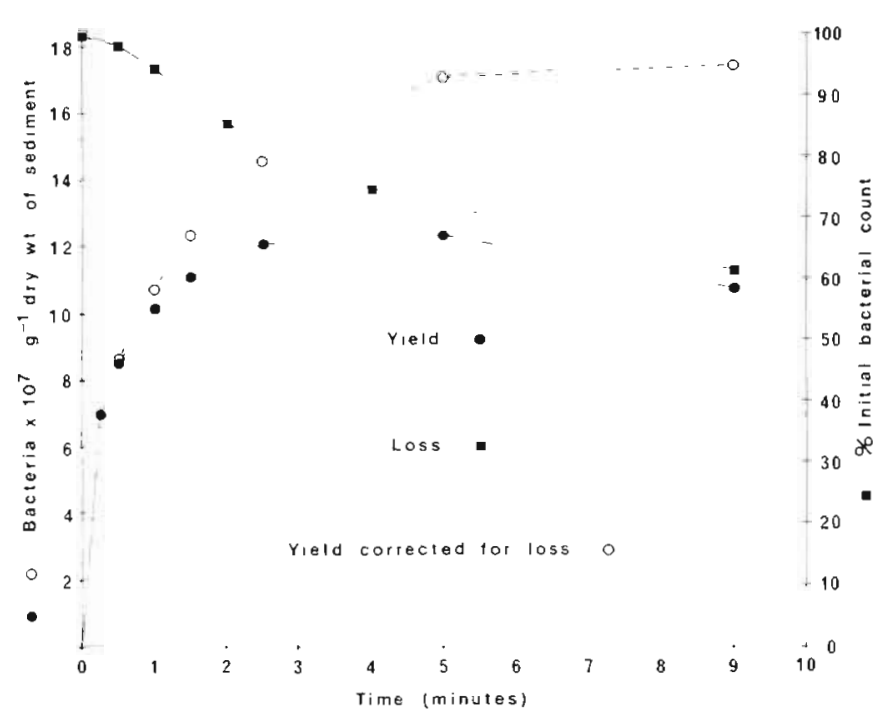

Fig. 4. Cumulative yield of attached sedimentary bacteria by ultrasonication $(\bullet)$ and these values corrected for destructive losses $(O)$ measured by ultrasonication of a natural suspension of bacteria extracted from sediments by 2 min homogenization ( $(\boldsymbol{\square})$

mate number originally attached to the sediment. At 9 min the curve of the yield corrected for loss appears to have attained its asymptote and the results obtained after optimum treatment are increased to this level when multiplied by a factor of 1.44 .

These experiments thus indicate not only that ultrasonication is more effective than homogenization in extracting formalin-fixed attached sedimentary bacteria, but also that subsequent bacterial counts need careful evaluation and correction for losses caused by damage during extraction. The correction factor pro- 
vided above will be useful in our work but will not necessarily be applicable to sediments from other environments. However, in magnitude it highlights the extent to which direct counts need to be adjusted to reflect actual numbers attached to the sediment under study.

Acknowledgements. This research was financially supported by the South African Association for Marine Biological Research and the Natal Town and Regional Planning Commission.

\section{LITERATURE CITED}

Anderson, J. G., Meadows, P. S. (1969). Bacteria on intertidal sand grains. Hydrobiologia 33: 33-45

Cassell, E. A. (1965). Rapid graphical method for estimating the precision of direct microscopic data. Appl environ. Microbiol. 13: 293-296

Dale, N. G. (1974). Bacteria in intertidal sediments: factors related to their distribution. Limnol. Oceanogr. 19: 509-518

Dye, A. H. (1979). Measurement of biological oxygen demand in sandy beaches. S. Afr. J. Zool. 14:55-60

Frobisher, M., Hinsdill, R. D., Crabtree, K. T., Goodheart, C. R. (1974). Fundamentals of microbiology, 9th ed. Saunders, Philadelphia

Hobbie, J. E., Daley, R. J., Jasper, S. (1977). Use of Nuclepore filters for counting bacteria by fluorescence microscopy. Environ. Microbiol. 33: 1225-1228
Koop, H., Griffiths, C. L. (1982). The relative significance of bacteria, meio- and macrofauna on an exposed sandy beach. Mar. Biol. 66: 295-300

Meyer-Reil, L. A., Dawson, R., Liebezeit, G., Tiedge, $H$. (1978). Fluctuations and interactions of bacterial activity in sandy beach sediments and overlying waters. Mar. Biol. 48: 161-171

Montagna, P. A. (1982). Sampling design and enumeration statistics for bacteria extracted from marine sediments. Appl. environ. Microbiol. 43: 1366-1372

Puleo, J. R., Favero, M. S., Petersen, N. J. (1967). Use of ultrasonic energy in microbial contamination on surfaces. Appl. Microbiol. 15: 1345-1351

Scheraga, M., Meskill, M., Litchfield, C. D. (1979). Analysis of methods for the quantitative recovery of bacteria sorbed onto marine sediments. In: Litchfield, C. D., Seyfried, P. L. (ed.) Methodology of biomass determinations and microbial activities in sediments. American Society for Testing Materials, Philadelphia, p. 21-39

Stevenson, I. L. (1958). The effect of sonic vibration on the bacterial plate count of soil. Plant and Soil 10: 1-8

Weise, W., Rheinheimer, G. (1978). Scanning electron microscopy and epifluorescence investigation of bacterial colonization of marine sand sediments. Microb. Ecol. 4: 175-188

Williams, A. R., Slade, J. S. (1971). Ultrasonic dispersal of aggregates of Sarcina lutea. Ultrasonics 9:85-87

Zvyaginstev, D. C., Galkina, G. M. (1967). Ultrasonic pretreatment of soil for microbiological assay. Mikrobiologiya 36: 1087-1095

This paper was submitted to the editor; it was accepted for printing on September 30, 1983 